\title{
A IMPLANTAÇÃO DA TELEFONIA EM BELÉM DO PARÁ E OS REFLEXOS DA MODERNIDADE PARA A POPULAÇÃO (1881-1889)
}

\author{
Alessandro Pacheco Frazão ${ }^{1}$ \\ Raimundo Nonato de Castro ${ }^{2}$
}

\begin{abstract}
RESUMO: O presente artigo analisa o processo de implantação da telefonia em Belém do Pará nos anos de 1881 a 1889, ao mesmo tempo em que evidencia o contexto da economia da borracha que foi essencial para este processo. Belém se tornou porto escoador da produção gomífera e, com isso, apresentou um aumento na arrecadação para os cofres públicos, fato esse que possibilitou investimentos em grandes obras públicas, como as reformas urbanas na educação, saúde e transporte público, dessa forma, atraindo o denominado "progresso e modernidade". Um dos sinais dessa modernidade foi o telefone, que impulsionou o mercado de bens e serviços na cidade, trazendo o ar da modernidade para a elite local, da época.
\end{abstract}

PALAVRAS-CHAVE: Borracha. Modernidade. Telefonia. Amazônia.

ABSTRACT: This article analyzes the process of deployment of telephony in Belem in the years1881-1889. At the same time, it shows the context saving the rubber which was essential for this process. Belém became the spill way port rubber production, it had an increased tax revenue to state coffers. What enabled investments in major public works such as urban reforms in education, health, public transport, attracting the so-called "progress and modernity."One of the signs of that modernity was the telephone, which boosted the market for goods and services in the city, bringing air of modernity to the local elite of the time.

KEYWORDS: Rubber. Modernity. Telephonic Services. Amazon.

\section{Introdução}

O processo de modernização ocorrido na cidade de Belém, no fim do século XIX e no início do XX, pode ser entendido, de acordo com SARGES (2002) como um processo de modernidade que trouxe a "Belle Époque" e que ampliou as possibilidades econômicas e culturais, além proporcionar o avanço das tecnologias ${ }^{3}$. Estes avanços ocorridos em Belém só

\footnotetext{
${ }^{1}$ Alessandro Frazão é Licenciado em história pela Faculdade Integrada Brasil Amazônia - FIBRA; e-mail: aletec81@ hotmail.com. https://orcid.org/0000-0001-5470-9232;

${ }^{2}$ Raimundo Castro é Doutor e Mestre em História pela Universidade Federal do Pará. Professor do Instituto Federal de Educação do Pará; e-mail: castro_nonato@ hotmail.com. https://orcid.org/0000-0002-0687-9197.

${ }^{3}$ Nesta obra a autora aborda os aspectos considerados essenciais na construção de uma cidade considerada moderna e civilizada. Para tanto analisar os relatórios de governo, bem como o código de postura instituído pela administração municipal. A ideia de modernidade surge, segundo Le GOFF (2003: 190), a ação modernizadora carrega consigo uma visão na qual coloca a cultura submissa a outra. Importa observar que na modernização “(...) as nações atingidas pelo imperialismo ocidental (...) foram confrontadas com o problema do atraso em certos campos". Esta ideia relacionada ao sentido de modernidade, gerou nas nações consideradas "atrasadas" a necessidade em aderir a um projeto de modernização com base no modelo europeu.
} 
foram possíveis graças à valorização de alguns produtos da região, cujo principal foi a borracha, que, a partir da segunda metade do século XIX, levou a inserção da Amazônia no sistema capitalista mundial. A economia da região passou a girar em torno do látex, a partir de 1840. Em decorrência dessa nova ordem econômica, Belém assumiu o papel de principal porto de escoamento da produção gomífera, canalizando parte do excedente dessa economia para os cofres públicos, possibilitando investimento na área urbana.

Importante destacar que a urbanização, aliada ao crescimento das cidades, proporcionou uma alteração de comportamento entre o público e o privado, ou seja, o estado passou a interferir no modo de pensar e agir da população. Portanto, as ruas e praças passaram a ser o local de propagação de novos valores, e que levou a um excessivo controle social sobre as camadas desfavorecidas da população. Sidney Chalhoub (1996) destaca que ocorreu um processo de reforma na cidade do Rio de Janeiro, em fins do século XIX, onde o discurso de higienistas contra habitações coletivas interessou sobremaneira a grupos empresariais atentos às oportunidades de investimentos abertas com a expansão e a transformação da malha urbana da corte.

Em relação à política de urbanização e higienização da cidade de Belém, percebem-se mudanças introduzidas na capital do Pará. Na área considerada central, houve um intenso processo de revitalização, pois, foi inserido o sistema de esgoto, coleta seletiva, construção de fornos crematórios, além da reforma e construção de novas praças. Os bondes elétricos foram uma das grandes novidades deste processo de urbanização. Contudo, a historiografia não faz referência à implantação dos telefones. Embora estivessem inseridas nesse contexto, não há, no século XIX, estudos acadêmicos relacionados à implantação da telefonia em Belém. Sendo assim, este trabalho ganha relevância, pois foi produzido e embasado em fontes de jornais da época. O objetivo desse trabalho é, portanto, explicar a importância do processo de implantação da telefonia em Belém e suas vantagens, como a comodidade para aqueles que possuíssem esse serviço, e para a economia da cidade, como resultado do período da produção gomífera.

Além disso, este artigo procura mostrar e compreender como os indivíduos incorporaram ao seu cotidiano essa inovação tecnológica, e de que maneira as modificações e alterações foram inseridas nos ritmos e rotinas da vida da sociedade paraense. As pessoas começaram a familiarizar-se com a ciência e com as novas tecnologias, buscando, sobretudo a sua adaptação. O telefone passou a fazer parte desse novo cotidiano, permitindo ligações instantâneas entre pessoas, ao mesmo tempo em que ampliou as atividades comerciais na/e além da cidade. 
Dentre as atividades mais comuns praticadas com a telefonia, têm-se os anúncios nos jornais A Província do Pará e o Diário de Belém, que foram transcritos para uma linguagem mais atual com o intuito de facilitar o entendimento sobre essas fontes. Esses dois jornais tinham em suas páginas anúncios de fábricas, farmácias e profissionais liberais, como os advogados e os médicos, sendo esses últimos a grande maioria. Utilizavam os serviços para atender as famílias dos seringalistas da época, dando mais comodidade a elite social da época. Os jornais eram utilizados, também, pela a Empresa Paraense de Telefones para informar sobre novos números de telefones, manutenção da rede e as novidades de novos aparelhos que vinham da Europa.

\section{Belém rumo à modernidade}

Para melhor compreensão do processo de implantação da telefonia em Belém do Pará e seu conceito de modernidade, é preciso entender o contexto econômico. No início do século XIX, a produção e o comércio do Pará, junto com a região amazônica tiveram relevância, pois estavam ligados diretamente à Europa, já que apresentava elementos do sistema do antigo regime colonial. Ressalta-se que, a economia pautou-se nas coletas das drogas do sertão, que eram produtos como canela, frutas, plantas medicinais entrou outras. Somente a partir da segunda metade do século XIX é que o Pará obteve um grande desenvolvimento econômico em decorrência da produção e exportação do látex, que ganhou estimulo maior em 1840, com a descoberta da vulcanização por Charles Goodyear, e a manufatura da borracha paraense destacou-se no mercado, pois produziu e exportou, segundo a historiadora Maria de Nazaré Sarges, sapatos, revestiu mochila militares, além de outros artefatos.

O auge da produção da borracha, na segunda metade do século, gerou uma grande movimentação econômica, em particular, em Belém, pois a cidade acabou sendo porto escoador da produção gomifera, canalizando recursos para as principais obras públicas, como na área urbana, educacional, saúde, transporte público e tecnologia, neste caso, por exemplo, com a implantação da telefonia, que se destacou como um elemento da modernidade. Essa última trouxe consigo a ideia de uma sociedade baseada nos valores da razão, na industrialização da produção transformadora do conhecimento científico em tecnologia.

Este conceito se deu devido à industrialização que estava em alta e, a sociedade pautava-se nos padrões europeus, os quais procuravam se adequar as tecnologias, rompendo com antigos hábitos. Para Paolo Rossi (2010) a ideia de progresso apresentava convicções: em primeiro lugar, havia uma lei que em vários graus de fases ou etapas conduz à perfeição e 
felicidade da humanidade; já em segundo, o processo de aperfeiçoamento, em regra identifica-se com o desenvolvimento e crescimento do saber científico; por último, a ciência e técnica destacam-se como as fontes principais que levariam ao progresso moral e político, o que confirmaria a ideia de progresso. Este conceito se refere ao homem, que precisa passar por três fases de desenvolvimento em sua vida para atingir o progresso.

Neste sentido, para Ortiz (1991), há duas modernidades, a primeira que associa a modernidade com a revolução industrial como, por exemplo, a construção de estradas de ferro, iluminação a gás, telégrafo e telefonia, e a segunda pelo emprego da técnica, ou seja, o aperfeiçoamento do que já foi criado, como automóvel, avião, eletricidade, telecomunicações e cinema. O autor deixa claro que essa segunda modernidade do século XIX será recorrente no século XX. Com isso, Belém foi aos poucos percebendo o sinal de modernidade no momento em que passou pelo processo de melhoramento, urbanístico, saúde, transporte público e a telefonia.

\section{Uma breve história da telefonia no Brasil}

Antes de debater o tema sobre a introdução da telefonia no período de 1881 a 1889 , é importante destacar como ocorreu a chegada da telefonia no Brasil, de modo que se possa ter uma melhor compreensão do assunto tratado neste artigo. $\mathrm{O}$ telefone foi inventado, em março de 1876, pelo escocês Alexander Graham Bell. Nesse mesmo ano, visitando a exposição comemorativa do centenário da independência dos Estados Unidos, realizada na Filadélfia, o imperador Pedro II foi convidado pelo inventor a examinar sua "máquina falante". A visita e, sobretudo, a admiração do imperador brasileiro contribuíram para atrair a imprensa para o telefone, que, até então, era considerado um simples brinquedo. Pedro II determinou a instalação de um aparelho no palácio da Quinta da Boa Vista, ligando-o as residências de seus ministros. O serviço de montagem foi realizado pelo "Western and Brazilian Telegrafh Company”.

Os circuitos (ou comutação telefônica) foram inaugurados em 1877. O primeiro aparelho telefônico que se tem notícia no Rio de Janeiro foi exposto naquele mesmo ano, na casa comercial "O Grande Mágico" - especializada em novidades mecânicas e aparelhos elétricos. Ainda em 1877, a firma "Rhode \& Co" estabeleceu a ligação de seu escritório, na 
Rua do Ouvidor, ao quartel do corpo de bombeiros, enquanto o ministro da agricultura providenciava a ligação de seu gabinete com diversas repartições da Corte ${ }^{4}$.

$\mathrm{Na}$ década de 1880, as redes telefônicas experimentaram um crescimento considerável em todo mundo. Em 1887, já havia mais de 150 mil assinantes nos Estados Unidos; 26 mil na Grã-Bretanha; 22 mil na Alemanha; 9 mil na França; 9 mil na Itália e 5 mil no Brasil. Dois anos antes existiam apenas três estações telefônicas no Rio de Janeiro, com 1.675 assinantes, em Pernambuco eram duas as estações com 275 assinantes, e na Bahia também duas com 245 assinantes (EMBRATEL, 1965/1997, p. 10).

O decreto $\mathrm{n}^{\circ}$ 8.065, de 17 de Abril de 1881, autorizava a "Telephone Company of Brazil" a funcionar, no entanto, haveria um representante do Império com plenos poderes para decidir sobre todas as contestações que se suscitarem, quer com o Governo, quer com os particulares. Todas as transações e operações que a companhia efetuasse no Império seriam reguladas pela legislação do Brasil, e julgadas pelos seus Tribunais. Importante destacar que, apesar de haver concedido a execução dos serviços de telefonia, o governo imperial exerceria um controle sobre este serviço.

$\mathrm{O}$ decreto $\mathrm{n}^{\circ}$ 8.453-A, de 11 de Março de 1882, estabeleceu bases para a concessão dos serviços telefônicos, ou seja, a implantação das linhas telefônicas tinha que ser feita de acordo com a repartição dos Telégrafos, documentando tudo em escrito. Por outro lado, o fio dessas linhas telefônicas não poderia passar por cima das linhas do Estado, de modo que, por qualquer corte ou ruptura, a empresa seria penalizada. $\mathrm{O}$ concessionário ou a empresa teriam que organizar a distribuição dos fios, de modo que não poderiam estar sobre os tetos das residências, e deveriam, ainda, fincar os postes nas ruas e estradas por sua conta, observando, desta maneira, os códigos de posturas municipais, além de resguardarem possíveis indenizações a que tiverem direito os proprietários atingidos por este serviço. A rede telefônica, portanto, estaria submetida à fiscalização do Governo. Para esse fim os prepostos da Diretoria Geral dos Telégrafos teriam o direito de entrar, em qualquer ocasião, na estação central, e proceder ao exame que julgassem convenientes. A concessão duraria quinze anos, durante os quais não poderia ser autorizada empresa idêntica dentro da mesma região.

\footnotetext{
${ }^{4}$ Segundo a obra Memória e História da Embratel 1965/1997, a primeira concessão para construir e operar linhas telefônicas no Rio de Janeiro foi dado em 1879, a Charles Paul Mackie. Representante da Bell Telefhone Co, no Brasil, um grupo de empresários norte-americanos ligados a Mackie organizou a Brazilian Telefhone Company, em outubro de 1880, e em maio do ano seguinte estavam instalados os três primeiros telefones comerciais públicos do Brasil. A concessão decretada em abril de 1881, dava permissão à firma de operar e instalar linhas no Rio de Janeiro e em seus subúrbios e em Niterói. Em 1883, havia 800 assinantes no Rio e 200 na capital fluminense, bem como já se encontrava em funcionamento a primeira linha interurbana do país ligando a capital do império a Petrópolis. No início de 1884, a companhia de telégrafos urbanos instalou os primeiros 11 telefones de assistentes comerciais e residenciais de São Paulo. (EMBRATEL, 1965/1997, p. 10).
} 


\section{A telefonia em Belém: 1881 a 1889}

O início do processo de implantação da telefonia, em Belém, se deu em 1881, ou seja, ainda no período imperial. Com a implantação da República, em 1889, fortaleceu ainda mais a ideia de modernidade que a cidade então buscava. Fazendo análise dessa questão, os republicanos destacavam que o império era tido como sinal do atraso e a república trazia os ares da modernidade, porém, sendo breve nessa observação, os discursos sobre os ideais de república tiveram de ser feitos por símbolos ou imagens, na medida em que a maioria da população tinha um grau pequeno de educação formal (CARVALHO, 1990. p. 10). Neste sentido, o telefone representaria o progresso para a Amazônia.

Percebe-se que, entre anos de 1881 e 1889, houve um grande crescimento na área da telefonia em Belém do Pará. No entanto, deve-se analisar que este progresso não se deu por acaso, pois em meados da segunda metade do século XIX, Belém foi redesenhada com a extração da borracha, que se destacou por ser uma fonte de renda importante e que impulsionou a economia local. Sarges (2002), ao analisar essa questão, relata que o processo de modernização da cidade de Belém só foi possível em razão do enriquecimento que atingiu certos setores sociais da região a partir da segunda metade do século XIX ${ }^{5}$.

O jornal Diário de Belém, de 25 de janeiro de 1881, destacava a cotação da borracha no mercado nacional. A partir da informação publicada, pode-se afirmar que a borracha ocupava um dos primeiros lugares em termos de produção, o que consequentemente aumentava a arrecadação. Diante disso, o governo e a imprensa passavam a colocar nas páginas dos periódicos os valores desse produto no mercado, o que caracterizaria uma fiscalização imposta sobre o mesmo. Noutra publicação, um artigo, do mesmo jornal, datado de 5 de janeiro de 1881, enfatizou a introdução da telefonia na cidade de Belém, o texto é assinado pelo secretário Dr. Camilo H. Salgado que relatava:

"De ordem do senhor Exm.Sr presidente desta câmara municipal de Belém
faço, público para o conhecimento dos municípios, que se acha em vigor a
postura a baixo transcrita organizada pela mesma camará aprovada pelo
Exm.Sr presidente da província como da seguinte portaria:5 $5^{\circ}$ seção- N.898-
O presidente, da província em consideração o exposto pela câmara municipal

\footnotetext{
${ }^{5}$ Reforçando o processo de inserção da Amazônia no sistema capitalista mundial, toda atividade econômica passou a girar em torno da borracha a partir de 1840. Em decorrência dessa nova ordem econômica, Belém assumiu o papel de principal porto de escoamento da produção gomífera, canalizando parte desse excedente que se originou dessa economia para os cofres públicos, os quais direcionaram o investimento para área do urbano, com calçamentos de ruas com paralelepípedos de granito importados da Europa, construção de prédios públicos, casarões em azulejos, monumentos, praças e etc. (SARGES, 2002 p.14).
} 
da capital em 27 de novembro último, resolve, usando da autorização, conferida no art. $2^{\circ}$ da lei 1.831 aprovar provisoriamente os dois artigos de postura abaixo transcritos formulados pela referida câmara, a fim de serem observados desde já e oportunamente submetidos a aprovação da Assembleia Provincial em sua próxima reunião. Art.1 É permitido com licença da câmara, o uso de telefone de uma casa para outra, contanto que o fio condutor seja colocado no alinhamento das casas com o consentimento dos seus proprietários atravessando somente nas ruas, travessas e em estradas em linha retas nos lugares absolutamente indispensáveis. O infrator incorrerá na multa de dez mil réis, os que já estai colocados não poderão ser reparados senão de acordo com as disposições desta postura. Art. $2^{\circ}$ Sempre que para colocação dos fios condutores haja a necessidade de coloca se pilares, devem ser este de boa madeira, de uma só altura, lavrados e pintados, não podendo ser colocados juntos aos lampiões de iluminação pública ou centro de praças. O infrator pagará dez mil réis de multa, sendo os pilares arrancados à custa do infrator. Palácio da Presidência do Pará, 24 de dezembro de 1880 (assinado) José da Gama Coelho e Abreu- conforme- servindo de oficial maior, João Luiz Coelho. Secretaria da Câmara Municipal de Belém do Pará, 27 de dezembro de 1880 Camilo H. Salgado secretario" (DIÁRIO, 05/01/1881, p. 3).

Percebe-se, com este decreto, que a telefonia aqui instalada deveria seguir regras e adequações aos padrões da cidade, pois foi criado um conjunto de normas técnicas para a implantação com cabos e portes de madeira no seu devido lugar, sob pena de multa para quem não cumprisse o decreto. Após a publicação do ato, a execução dos serviços foi possível com a entrada da companhia telefônica "Telephone Company of Brazil", que fazia parte do grupo que implantou com sucesso os telefones nos Estado Unidos. Importa lembrar que essas companhias escolheram um ponto central da cidade para fazer seu escritório e que também passou a servir como central telefônica, até onde chegava à fiação de todos os assinantes, possibilitando a todos se comunicar, bastando avisar ao empregado da companhia que girava uma chave magnética, que ficava no telefone, fazia-se a solicitação à telefonista indicando para quem seria a ligação, e depois bastava ligar para o empregado da companhia novamente para que ele desconectasse os cabos da central pública (Diário, 1/03/1881, p. 2). Com esse serviço, a população ganhava tempo e comodidade.

A introdução do telefone impulsionou o comércio, em especial, os serviços dos profissionais liberais. Vale destacar que, a empresa que veio à Belém realizou o trabalho a mando do comerciante português Carlos Monteiro e Souza, nos termos de concessão por meio do decreto imperial de número 8.344, de 17 de dezembro de 1881 (RELATÓRIO, 1908, p. 198).

Sobre a comodidade do telefone, também era notório que essa novidade conseguiu atender às necessidades dos órgãos públicos, que poderiam dar agilidade em processos que estavam parados, e esperando alguma resposta de outro órgão, pode-se argumentar este 
questionamento, a partir da notícia dada pelo Diário de Belém, do dia 1 de março de 1881, quando o juiz da vila de Igarapé-Miry solicitou informações de Belém da nova lei eleitoral. O juiz irritou-se, conforme se percebe no texto publicado no Diário de Belém, intitulado "Muito pode o progresso":

Aqui vai uma novidade, que o público talvez ignore: já há telefone desta capital para vila de Igarapé-Miry, esta importante notícia encontramos ontem na folga oficial, como? Entenda leitor: vem um ofício do juiz municipal daquela vila, consultando a presidência sobre diversas duvidas que lhe sugeriu a nova lei da reforma eleitoral, datada no dia vinte e quatro de abril, e no dia seguinte, dia vinte e cinco dava S.Exe. resposta a essa consulta, depois de ter sem dúvida estudado a lei. A não ser por meio de telefone, não encontramos outra via de comunicação tão fácil que pode se trazer a consulta feita em um dia e levada a resposta no dia seguinte.se a folha oficial quiséssemos explicaria a onde está o gato? (DIÁRIO, 12/05/1881, p. 2).

Ao que parece, isso se deu por causa da pressa do juiz da comarca, que queria respostas às suas indagações. Analisando este episódio, percebe-se que há um questionamento sobre a velocidade da informação, e que o telefone passou a ser um instrumento de trabalho necessário para essas pessoas, o que facilitou suas atividades profissionais.

A informação sobre a telefonia tornou-se tão importante que com o passar do tempo acabou sendo introduzida na estrutura jornalística. Em 1885, já havia uma coluna no jornal "Diário de Belém" denominada "O telefone transmitiu ontem", onde jornalistas recebiam notícias sobre a câmara municipal, chefaturas de polícia e reclamações de moradores. Porém, o desenvolvimento também acabou trazendo alguns transtornos para algumas pessoas, para termos ideia, no dia 25 de fevereiro de 1886, uma notícia deixava clara a crítica à implantação dos postes:

Em cidade alguma do mundo civilizado se encontrará, sobre os passeios, postes telefônicos, e que portes santos Deus, esses, que com prejuízo grosso do bom senso e da estética, fez a empresa colocar na rua dessa capital! Eles embarcaram sem necessidade o transito público e prejudicaram a estética, mesmo que fossem de ferro polido! (DIÁRIO, 25/02/1886, p. 2).

Ficava evidente a crítica à empresa que colocou os portes de telefonia, o que segundo o autor, agredia a estética da cidade. Portanto, a culpa pelo embaraçamento do trânsito público era do governo que havia concedido tal autorização para implantação deste serviço. Antes do processo de telefonia, a estética da cidade era encarada por todos como motivo de orgulho, pois estava enquadrada nos moldes europeus. Observa-se que o responsável pelo artigo deixava claro que "nem se fosse de ferro polido" ficaria bem, ou seja, era de madeira grossa, e tal implantação dependia de autorização também do particular.

Estes postes são em toda parte colocados sobre platibandas nos prédios, precedendo consentimento ou ajuste com os respectivos proprietários, nunca 
nas ruas e sobre tudo em portes tão grosseiros, como esses que ai se acham fincados sobre os passeios. Chamamos para este assunto a atenção da ilustríssima câmara e lhe pedimos encarecidamente que não descuide deste assunto, que é de molde a caracterizar o nosso desleixo. $\mathrm{O}$ troco do que consente a câmara no embaraço que tais portes trazem ao transito, e com que título autoriza o rompimento dos passeios? A câmara tem a polícia das ruas; mais é seu o calçamento que é assim estupidamente mutilado pela empresa telefônica? Os passeios sabem todos, foram construídos à custa dos prédios uns pagos pelos respectivos proprietários e outros do tesouro, que tem ultimamente custeados os calçamentos e com eles a construção dos passeios. Mas acudirão deste ou daquele modo, estão sob a administração da municipalidade! Estão, sim, sob administração da câmara, cujos deveres são de administrador e tem por fim sua conservação e não sua destruição. Para colocar os portes mutila a empresa os lajedos que ficam emprestáveis. Já teve o distinto presidente da câmara ocasião de observar estes postes e como estão colocados? (DIÁRIO, 26/02/1886, p. 2).

Percebe-se outro questionamento sobre os prejuízos causados pelos postes e a reclamação do morador sobre a câmara municipal que nada fez para intervir, questionando seus deveres e autoridade, e quem acaba pagando a conta dessa destruição, são os cofres públicos:

Para os fios telegráficos mesmo se não fincam postes nas ruas ou nas praças, ou eles se adaptam aos prédios ou são enterrados. O transito é que não é em caso algum embaçado nem a estética comprometida, mesmo a pretexto da utilidade que o telefone e o telégrafo sem a menor contestação trazem. Pense a câmara o que lhe incumbe: sua missão é de utilidade e sua existência se recomenda pelo bem não para o mal, os portes em questão constituem um escarro nas ruas da cidade e não podem continuar nos passeios e nas praças, parece que uma caveira de burro nos persegue. (DIÁRIO, 26/02/1886, p. 2)

Aqui é reconhecida a importância do telefone. Porém, quando o autor do artigo se refere ao termo escarro nas ruas, é justamente à quantidade de postes colocados. A telefonia passava por uma fase de crescimento muito grande, por isso, cada vez mais um número maior de postes era colocado para atender essa demanda:

Quando se começa aclamar em altos brados pelo embelezamento de nossas praças aparecem os portes telefônicos! Compreendemos que o expediente é cômodo a empresa; mais pode a câmara anuir em semelhante desespero? Que se entenda a empresa com os donos dos prédios, contrate sobre eles a sua colocação, é justo, é conveniente, mais que venha por economia atravancar as ruas, destruir os passeios e ofender a beleza da cidade, isso é demais, não lhe pede ser consentido, não deve, nem pode consentir a câmara, que tem a missão de fazer o bem, e não a de fazer o mal. É constrangidamente que nos dirigimos por esta forma a câmara de Belém, as quais mais queremos aplaudir; mais vai nisso nosso dever, do qual sempre procuramos desempenhar com isenção e patriotismo (DIÁRIO, 26/02/1886, p. 2). 
Deve-se entender que o passeio era um hábito praticado pela elite local onde passeavam mostrando suas vestimentas vindas de Paris, e de afirmação social. Com os postes nas calçadas, ocorreu um incômodo para boa parte da população, porém, esse incômodo estava relacionado à ideia de progresso, como exemplo, a possibilidade de chamar o médico para qualquer emergência e qualquer horário.

No dia 27 de fevereiro de 1886, foi publicado um anúncio convidando os jornalistas do jornal Diário de Belém para a inauguração do posto médico, o evento estava previsto para o próximo dia. O posto estava localizado na farmácia Minerva de propriedade do senhor Elpidio R. da Costa, que inaugurou este novo serviço, o qual consistiu na implantação de um telefone na farmácia, na qual havia uma lista de médicos credenciados. Portanto, o cidadão, de posses, poderia ir a farmácia comprar um remédio simples ou marcar uma consulta com um médico credenciado e que atenderia a qualquer hora do dia e da noite (DIÁRIO, 27/02/1886, p. 2).

Essa atitude ajudou bastante à população que não possuía telefone para obter este tipo de serviços, pois, lembrando que o telefone era um bem que poucos possuíam. Primeiro pelo alto valor cobrado pela companhia, que deixava claro em seus anúncios que o pagamento de um ano de contas era adiantado para novos usuários de seus serviços. A Empresa Paraense de Telefones funcionava à travessa das Mercês $\mathrm{n}^{\circ} 18$, e quem tivesse interesse em obter uma linha, poderia procurar, também, em outros pontos da cidade. Como nos armazéns do Sr.Luiz Araújo \& Cia, La Rocque da Costa \& Cia, Barros \& Viana, Barros Lima \& Cia, Centro Comercial Paraense, Livraria Universal e lojas Esmeraldas, onde se podem obteriam mais esclarecimentos (DIÁRIO, 27/02/1886, p. 2).

No dia 2 de julho de 1888, na primeira página do jornal Diário de Notícias, uma nota informava sobre a venda da concessão da Empresa Paraense de Telefonia. A empresa passava das mãos do S.r: Carlos Montenegro para a firma Chermon, Aguiar \& Cia (DIÁRIO, 06/06/1886, p. 1). Sem qualquer responsabilidade, esse artigo, foi divido em três notas, publicadas no mesmo jornal, comprovando a compra da concessão, sendo que a data da compra de fato ocorreu no dia 28 de junho de 1888. Com a concessão para a empresa Chermon, Aguiar\& Cia, possibilitou-se a expansão da telefonia em Belém, com preços mais baratos e acessíveis a população. A partir de então poderiam solicitar a instalação do seu telefone pagando apenas a mensalidade e não adiantando um ano de pagamento. Caso o cidadão resolvesse ficar com dois telefones ganharia, ainda, $20 \%$ de desconto nas mensalidades. Neste sentido ocorreu melhorias nos serviços, já que os esclarecimentos ao público via notas de jornais enfatizavam esse avanço. 
Em 29 de novembro de 1888, foi publicado o decreto imperial, no entanto foi datado como de 30 de maio de 1888 dando livres poderes para todos os serviços de instalação e recuperação de cabeamento telefônico ${ }^{6}$. Em quase uma década, o telefone já havia sido implantado em Belém, interligando pessoas e serviços. O jornal A Província do Pará, em uma nota intitulada "O telefone", dava o reconhecimento sobre este bem que já era imprescindível, a publicação assim relatava:

Os telefones: Aceitamos hoje a publicação deste artigo, na convicção de uma breve história, de caráter não muito técnico, de uma das mais brilhantes descobertas da ciência moderna, não deixará de interessar a uma parte considerável da nossa população culta, à semelhança que se observa na América do norte e na Europa. Aqui, a imprensa, como em toda parte do mundo civilizado, tem sido sempre divulgadora das informações relativas ao progresso realizado na ciência e nas artes; e não se tem descuidado de prestar constante atenção aos agigantados estádios, transposto, nestes últimos tempos, no desenvolvimento dos numerosos e variados empregos da eletricidade (A PROVÍNCIA, 29/09/1889, p. 1).

Quando o artigo menciona que estava divulgando as descobertas da ciência moderna para uma parte da população, referia-se a elite local. Pode-se observar que o artigo relaciona a cidade de Belém com à América do norte e Europa, onde essa última era considerada como centro intelectual da época, em especial, a França por sua sofisticação.

O desenvolvimento da telefonia no Pará tem sido tão rápido e tão geral; a sua adaptação as necessidades tão peculiares da vida e das indústrias, tão imediata e inteligente, que consideramos como uma justa homenagem a esta simpática aceitação, a publicação de tudo o que diz respeito a essa portentosa descoberta. Neste, caso e como em tantos outros de natureza semelhante, o Pará deu prontamente sua adesão e apoio a este novo elemento de progresso material, tal demonstração se ainda fosse necessária, a presteza que sua população põe em contribuição toda e qualquer descoberta da ciência moderna que possa cooperar no adiantamento da sua própria indústria, concorrendo com maior comodidade para o viver de cada dia (A PROVÍNCIA, 29/09/1889, p. 1).

Analisando este artigo, percebe-se que o telefone já era visto como algo indispensável na vida do paraense e, que estava pronto para aderir a qualquer novidade tecnológica. A telefonia, portanto, facilitou a interligação das pessoas com as farmácias, médicos e empresas. A sociedade percebeu o quanto era importante à velocidade da informação para o cidadão no seu dia-a-dia. Já para as empresas, suas vendas melhoraram, mostrando, desse modo, que o povo paraense estava se adaptando às novas tecnologias, buscando assim o progresso.

\footnotetext{
${ }^{6}$ Empresa de propriedade de Francisco Leite Chermon, Justo Leite Chermon, Antônio Leite Chermon e Francisco Batista da Silva Aguiar. (DIÁRIO, 28/06/1888, p.1).
} 


\section{Reflexos da modernidade para a população de Belém}

Com a expansão da telefonia, Belém precisou catalogar números para facilitar a procura do serviço ou pessoas. Para isso foram criadas listas numéricas dos assinantes, e que, em alguns casos, foram publicadas nos jornais. A lista a seguir foi a primeira publicada no jornal "A Província do Pará”, em 1889. O detalhe da expansão da telefonia pode ser observado nos anúncios dos jornais. Antes, porém, para acessar algum tipo de serviço era preciso observar nos jornais a hora de atendimento como, por exemplo, um médico estaria em seu consultório a partir das $08 \mathrm{~h} 00$ e sairia ás $12 \mathrm{~h} 00$ para atender seus pacientes, caso contrário era necessário ir à casa do médico para tentar encontrá-lo ou só tentando em outro dia, no horário estabelecido pelos anúncios dos jornais. Isso se dava para praticamente todos os serviços da sociedade belenense do período. Contudo, com a implantação dos telefones, este quadro mudou, pois os próprios médicos publicavam anúncios destacando seus serviços e seus números de telefone, possibilitando que as famílias fossem atendidas em suas residências, o que gerou comodidade a uma parcela da população. Em outros casos ligava-se para casa do médico para obter ajuda.

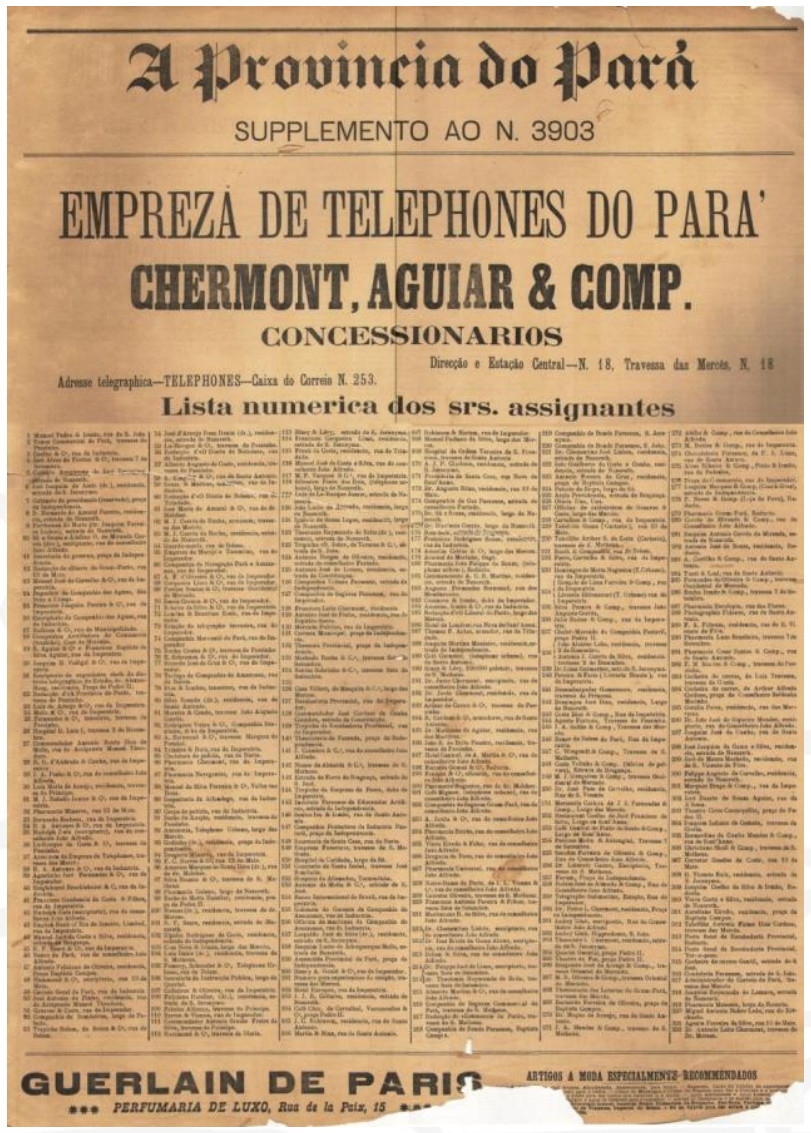

Imagem 1. A Província do Pará, Suplemento, Belém, 20 de junho de 1889.p. 5 
Os jornais, com o passar dos anos, receberam mais e mais anúncios com números de telefones, reforçando a sua importância na questão da comodidade do comércio, onde os profissionais puderam veicular seus serviços através dessa tecnologia. A lista destaca a relação numérica de assinantes publicada no jornal de circulação diária em Belém. Isso demonstra a expansão do serviço telefônico e o desenvolvimento de vários setores que passaram a utilizar o telefone para facilitar suas vendas, e a elite local que possuía seu nome nas listas. Importa lembrar que o telefone era um bem de alto valor econômico.

Além dessa lista, vários anúncios de profissionais liberais e de colégios particulares, foram publicados nos primeiros anos. Demonstrando o avanço vivido na cidade de Belém. Anúncios como do Colégio Americano (DIÁRIO, 01/01/1889, p. 6) ou mesmo do advogado Dr. Justo Chermont ${ }^{7}$ ganhavam espaço nas folhas dos periódicos paraense. Além dessas atividades também, estava nas páginas dos jornais, anúncios sobre as fábricas existentes na cidade, como a chocolateria Paraense.

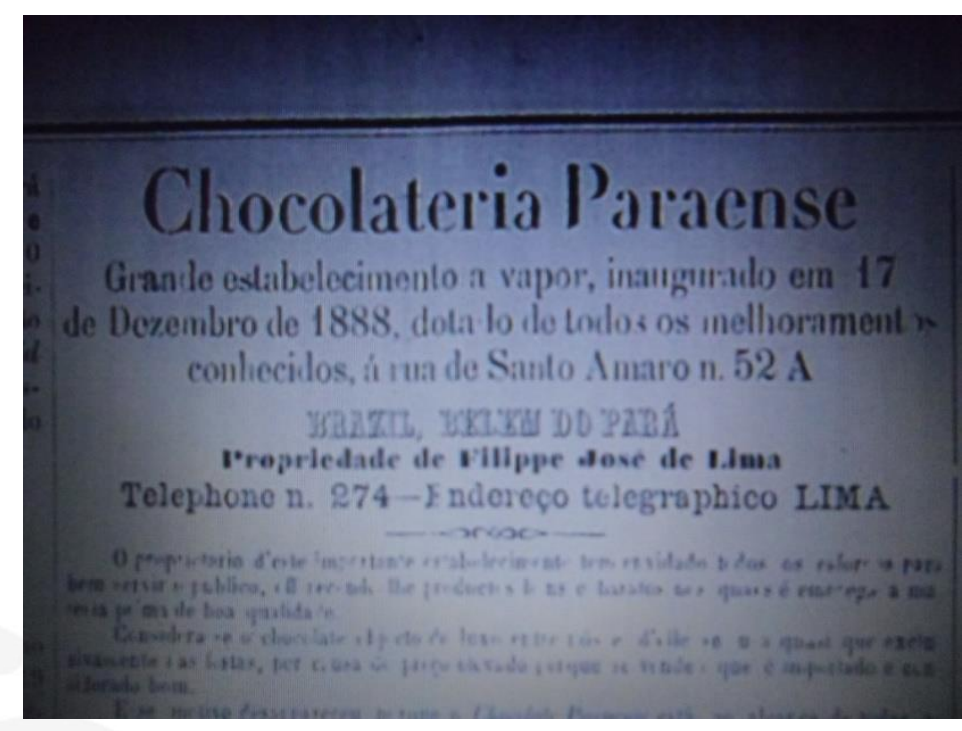

Imagem 2. Chocolateria Paraense, Diário de Belém, 11 de agosto de 1889 p.4.

A figura acima destaca no campo da indústria a Chocolateria Paraense, onde, com a introdução da telefonia, foi capaz de manter contato com seus clientes de forma mais rápida e agilizar seus negócios. Além de demonstrar os avanços para as atividades comerciais trazidas pela implementação da telefonia na capital do Pará, ficava evidente a quantidade de fábricas e

\footnotetext{
${ }^{7}$ Justo Chermont foi responsável pela fundação do clube Republicano no Pará, tendo sido governador do estado do Pará. O Diário de Belém, de 22 de janeiro de 1889 (p. 6), anunciava todas as informações necessárias para contactar o advogado, seja no escritório ou mesmo na sua residência. Chermont atendia casos jurídicos tanto na capital quanto no interior da província.
} 
serviços disponíveis a uma pequena parte da população da cidade e que se enquadrava na condição de elite paraense.

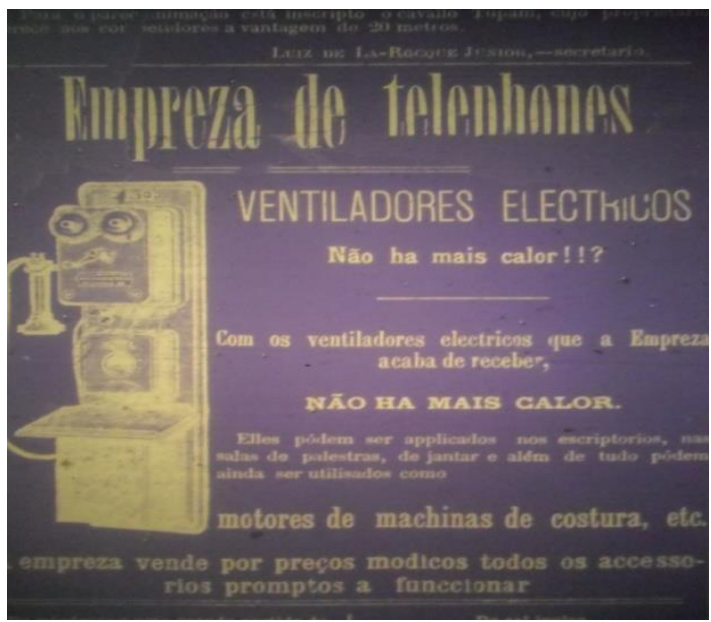

Imagem 3: Empresa de telefones ${ }^{8}$, A província do Pará, 11 de setembro de 1889 p.1.

Neste anúncio da Empresa de Telefones, percebemos que o ramo de trabalho ia além dos telefones, trabalhavam com motores, ventiladores, máquinas de costuras e no mês de dezembro com artigos para presentes. Mostrando claramente aos possíveis clientes a diversidade de serviços desempenhados pela empresa.

Algo comum nos anúncios ficava por conta do grande número de informações. A figura acima destaca o anúncio do Dr. Almeida Pernambuco informando os dias de seu atendimento em seu consultório e seus telefones tanto do escritório quanto da residência, podendo ser chamado a qualquer hora por seus clientes em emergências médicas.

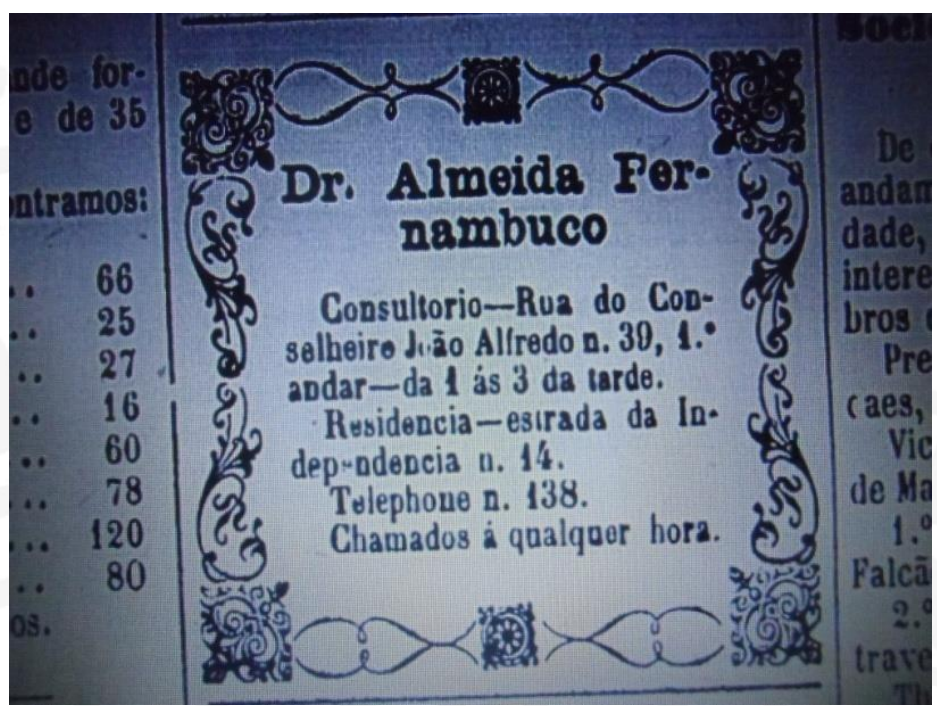

Imagem 4: anuncio Dr. Almeida Pernambuco, A Província do Pará 2 de outubro de 1889 p.3.

\footnotetext{
${ }^{8}$ A empresa de telefones, com o passar dos anos começou a trabalhar com vários, como motores elétricos, ventiladores, campainhas elétricas e artigos para presentes. A Província do Pará, Belém, 11/09/1889. p.1.
} 
Esses anúncios reforçam a ideia de progresso, comodidade e modernidade para a cidade de Belém. Neles estão vários segmentos que vão desde a área jurídica, industrial e serviços. Na imagem 4 percebe-se que o médico atenderia em horário e local fixo, pois era deste modo que seriam realizadas as consultas. A partir da introdução da telefonia, o médico poderia conseguir mais clientes, podendo agendar consultas ou colocar-se a disposição, em espécie de plantão. Portanto, caso o paciente precisasse dos serviços de urgência, poderia ligar para a casa do médico a qualquer hora do dia ou da noite, reforçando a importância desse serviço.

\section{Considerações finais}

A implantação da telefonia em Belém foi muito importante para o desenvolvimento da cidade, pois interligou pessoas e serviços, só lembrando que essa comodidade não atendia a todos os membros da sociedade, pois era um serviço de alto custo financeiro, que em boa parte da sua história atendia apenas a elite econômica. Embora se destacasse como um serviço elitizado, ocasionou queixas sobre sua a implantação na cidade, como no caso específicos dos portes colocadas nas calçadas, o que ocasionou transtornos nos passeios públicos.

Estes problemas gerados com a implantação da telefonia, estavam relacionados à ideia de desenvolvimento e do progresso. No entanto, isso foi deixado de lado já que se obtinham mais benefícios como os telefones, na medida em que a população buscava a velocidade das informações, beneficiando empresas, médicos, advogados, delegacias, ou seja, todos os segmentos podiam se interligar facilitando os serviços para uma parcela da população.

\section{Fontes}

A província do Pará. Os telefones. Belém, 28 de março de 1889, p.1.

A Província do Pará. Cotação da borracha. Belém, 6 de junho de 1889

Diário de Belém. Camará municipa. Belém, 5 de janeiro de 1881, p .3.

Diário de Belém. Cotação da Borracha. Belém, 23 de janeiro de 1881, p. 1.

Diário de Belém. Muito pode o progresso. Belém, 12 de maio de 1881, p. 2.

Diário de Belém. Telephone Company Brazil. Belém, 01 de março de 1881, p. 2.

EMBRATEL. Memória Histórica da Embratel 1965/1997. 
RELATÓRIO. O município de Belém, relatório da cidade de Belém 1907 apresentado em 1908, sobre a administração do intendente municipal Antônio José de Lemos.

\section{Referências bibliográficas}

CARVALHO, José Murilo de. A formação das almas: o imaginário da República no Brasil. São Paulo: Companhia das Letras, 1990.

CHALHOUB, Sidney. Cidade febril: cortiços e epidemias na corte imperial. São Paulo: Companhia das Letras, 1996.

LE GOFF, Jacques. História. In: LE GOFF, Jacques. História e Memória. $5^{\mathrm{a}}$. Campinas, SP: UNICAMP, 2003.

ORTIZ, Renato. Cultura e Modernidade. São Paulo: Editora brasiliense, 1991.

ROSSI, Paolo. O passado, a memória, o esquecimento: seis ensaios das histórias das ideias. São Paulo: Editora UNESP, 2010.

SARGES, Maria de Nazaré. Belém: Riquezas produzindo a Belle-Époque (1870-1912). Belém: Paka-Tatu, 2002. 